\title{
Invernada dos Negros (SC): um povo enganado! um território retalhado!
}

\author{
Renilda Vicenzi ${ }^{1}$ \\ https://orcid.org/0000-0002-1304-573X \\ Eliane Taffare ${ }^{2}$ \\ https://orcid.org/0000-0001-9061-7781 \\ ${ }^{1}$ Universidade Federal da Fronteira Sul, Curso de História, Chapecó, SC, Brasil \\ ${ }^{2}$ Prefeitura Municipal de Chapecó, Secretaria Municipal de Educação, Chapecó, SC, Brasil
}

Invernada dos Negros (SC): um povo enganado! um território retalhado!

Resumo: O dia 20 de junho de 2004 é um marco na luta de mulheres e homens negras/os da comunidade rural 'Invernada dos Negros’, localizada nos municípios de Campos Novos e Abdon Batista - SC. Nesse dia a comunidade recebeu da Fundação Cultural Palmares a Certidão de Autorreconhecimento como 'Comunidade Remanescentes de Quilombos'. A trajetória até o Autorreconhecimento é centenária, e é marcada por resistências, pela permanência na terra e de afirmação da identidade negra. Este analisa parte dessa trajetória, quer seja a Ação de Divisão de terras "proposta" pelos verdadeiros herdeiros da terra - legatários, por meio de seu representante legal - advogado Henrique Rupp Junior, no ano de 1928 e concluída em 1942. Esta Ação de Divisão provocou o retalhamento da propriedade herdada, a usurpação, a exclusão e a desterritorialização das famílias negras. Incidindo ainda mais para a invisibilidade e negação da população negra naquele espaço, mas também impulsionará, décadas depois, a luta pela retomada da terra/território.

Palavras-chave: Famílias negras. Invernada dos Negros. Território. Ação de divisão.

Invernada dos Negros (SC): a deceived people! a shredded territory!

Abstract: The 20th of June 2004 is a milestone in the struggle of black women and men in the rural community 'Invernada dos Negros', located in the municipalities of Campos Novos and Abdon Batista - SC. On that day, the community received from the Palmares Cultural Foundation the Certificate of Self-recognition as 'Community Remnants of Quilombos'. The trajectory to Self-Recognition is centuries old, and is marked by resistance, permanence on earth and affirmation of black identity. This article analyzes part of this trajectory, whether it is the Land Division Action "proposed" by the true heirs of the land - legatees, through their legal representative - lawyer Henrique Rupp Junior, in 1928 and concluded in 1942. This division action caused the shredding of inherited property, usurpation, exclusion and dispossession of black families. Focusing even more on the invisibility and denial of the black population in that space, it will also drive, decades later, the struggle for the retaking of the land/territory.

Keywords: Black families. Invernada dos Negros. Territory. Share division.

Recebido em 25.02.2021. Aprovado em 15.05.2021. Revisado em 07.07.2021.

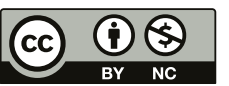

Este é um artigo publicado em acesso aberto (Open Access) sob a licença Creative Commons Attribution NonCommercial, que permite uso, distribuição e reprodução em qualquer meio, sem restrições desde que sem fins comerciais e que o trabalho original seja corretamente citado. 


\title{
Introdução
}

Em 07 de setembro de 2018, a Associação dos Remanescentes do Quilombo Invernada dos Negros e o Movimento Negro Unificado - SC emitiram uma nota de esclarecimento sobre a ocupação realizada pelos quilombolas no território da Invernada dos Negros, que se encontrava em domínio da empresa Imaribo (NOTA...; 2018). Na nota, explicitam que a ocupação ocorreu em função da morosidade no processo de titulação e as ações de (re)plantio de pinus pela empresa Imaribo com o intuito de não devolver o território. Ao encerrar a nota os quilombolas enfatizam: “Titulação Já! Reparação Já!” (NOTA..., 2018, p. 1).

A trajetória para titulação e reparação da comunidade negra rural denominada Invernada dos Negros é histórica, remonta o final do século XIX e está inserida no contexto social e político do pós-abolição. Era o ano de 1877 quando o fazendeiro Matheus José de Souza e Oliveira, em seu leito de morte, faz registrar suas últimas vontades - o testamento ${ }^{1}$-, nele deixa 'a terça parte de terras para seus escravos e libertos'. Esta terça parte compreendia a $89.096 .100 \mathrm{~m}^{2}$, cerca de 8 mil hectares, que deveriam permanecer aos legatários, sendo oito escravos, Domingos, Salvador, Manoel, Francisco, Geremias, Pedro, Jozepha e Innocência; e três libertos, Margarida, Damásia e Joaquim, e seus herdeiros, sem que houvesse em tempo algum, hipoteca, compra ou venda.

Ao longo do século XX esta propriedade foi retalhada e os descendentes dos legatários perderam parte significativa de seu território. A usurpação da terra significou a expulsão de famílias, o desmatamento e o isolamento dos que lá permaneceram. Ignorados em seus direitos básicos tornaram-se invisibilizados para o Estado e para as elites locais.

Com a redemocratização no Brasil e a promulgação da Constituição de 1988, que em seu Artigo 68 tem a seguinte redação: "Aos remanescentes das comunidades dos quilombos que estejam ocupando suas terras é reconhecida a propriedade definitiva, devendo o Estado emitir-lhes os títulos respectivos" (BRASIL, 1988), foi possível retomar o debate da territorialidade da comunidade. Pois, a identidade afirmada a partir dos sobrenomes e parentescos, a história, as memórias dos antepassados e seus legados, os locais de moradia e cultivo da terra, não foram extintos, e isso possibilitou a manutenção da luta por visibilidade e reconhecimento.

Em 2003, as famílias ali residentes fundaram a Associação Quilombola da Invernada dos Negros; e em abril de 2004, foi realizada uma audiência pública para abertura de inquérito de averiguação fundiária. Nesse momento, a então presidenta da Associação, a senhora Angelina Garipuna enfatizou:

\begin{abstract}
Nós sabemos que conforme está lá no Testamento, este terreno não era para ser vendido, não era para ser financiado e era para ser passado de geração em geração. Hoje somos um povo sofrido sem condições de sobreviver. Estamos aqui pedindo o resgate desses terrenos para que as nossas famílias possam voltar para a nossa comunidade e possam ter condições de viver. Somos um povo sofrido pela falta de terra sendo que a nossa descendência dos escravos, ganharam aquele terreno muito grande. Nós da Invernada dos Negros estamos aguardando e pedindo o reconhecimento da comunidade como remanescente de Quilombo. Nós queremos o nosso terreno de volta, se é nosso direito. (TAFFAREL; VICENZI, 2016, p. 4-5).
\end{abstract}

Nesse mesmo ano, o Instituto Nacional de Colonização e Reforma Agrária (INCRA) iniciou o processo para a regularização das terras, e ainda, o reconhecimento pela Fundação Cultural Palmares da Invernada dos Negros como comunidade remanescente de quilombo. Em 2006, foi concluído o laudo antropológico realizado pelo Núcleo de Estudos de Identidades e Relações Interétnicas (NUER) da Universidade Federal de Santa Catarina (UFSC) sobre a comunidade da Invernada dos Negros, e o mesmo pauta e afirma, a partir do uso de documentos (fontes primárias), cultura material e memória, ser aquele um território quilombola. A partir daí, não havia mais como negar a existência da comunidade. Contudo, a morosidade para regularização tornou-se o grande desafio aos quilombolas, que fortalecidos, passaram a reivindicar e exigir que o Estado devolvesse o que lhes é de direito.

No intervalo entre 1877 (testamento) e 2004 (reconhecimento de comunidade remanescente quilombola), gerações de famílias negras legatárias foram negligenciadas, arrancadas de sua terra e impossibilitadas, entre outros, de se alfabetizar, o que facilitou as ações dos outsiders em ser possuidores de títulos de áreas rurais de um território que não lhes pertencia. Este texto apresenta parte destas ações, mais especificamente a Ação de Divisão de Terras ${ }^{2}$ ocorrida entre os anos de 1928 e 1942, em que o advogado Henrique Rupp Junior passou 
a ser proprietário de $39.936 .000 \mathrm{~m}^{2}$, ou seja $50 \%$ do território, e ainda, na atualidade os legatários lutam pela restituição (LEITE et al., 2006).

\section{Famílias negras na Fazenda São João e na Invernada dos Negros}

O período pós testamento foi marcado pela formação da comunidade, com aumento no número de membros através de uniões matrimoniais, de nascimentos e consequentemente de moradias no local, que já no final do século XIX, era conhecido como Invernada dos Negros. Na terra herdada e junto aos seus formava-se uma comunidade negra rural. De acordo com Glória Moura (2006, p. 330):

Comunidade negra rural habitada por descendentes de africanos escravizados, com laços de parentesco. A maioria vive de culturas de subsistência, em terra doada, comprada ou secularmente ocupada. Valoriza tradições culturais de antepassados (religiosas ou não) e as recria no presente. Possui história comum, normas de pertencimento explícitas, consciência étnica.

Em pesquisa historiográfica sobre a comunidade (TAFFAREL, 2019), foi possível identificar a ancestralidade de Manoel, Damásia e Margarida, pois eram filhos da africana Josepha e do crioulo Domingos (todos mencionados no testamento), evidenciando que há uma história em comum. Esses, possivelmente viviam em união consensual e formavam assim, uma família, sendo os filhos nascidos na Fazenda São João. Por meio da análise de documentos eclesiásticos e cartoriais, foram identificados descendentes que vivem ainda hoje na comunidade. No entanto, destacamos que há um esquecimento e/ou apagamento dessa relação, inclusive nos processos judiciais, onde aparecem como terem deixado descendentes apenas Manoel, Damásia, Margarida e Francisco.

Reiteramos que o casal Josepha e Domingos deixaram descendentes e quiçá conheceram seus netos, filhos de Manoel de Souza com Ignácia de Meira Goes, de Margarida de Souza com Domingos Fernandes da Silva e de Damásia com Deoclécio Caripuna. Não sabemos se Francisco de Souza (depois, Francisco dos Santos) chegou criança ou adulto à fazenda São João, mas parte de sua prole da união com Maria Izabel do Espírito Santo tornou-se legatária (TAFFAREL, 2019, p. 84, 101, 118, 135).

Francisco era oriundo de outra escravaria, o que nos leva a pensar sobre a compra e venda de escravizados para as fazendas de criatórios e de produção de alimentos para consumo interno, fato presente nas fazendas oitocentistas dos campos do atual planalto catarinense. Também demonstra que o senhor Matheus de Souza e Oliveira, ao nominar oito escravizados e três libertos no testamento, para este local e no período oitocentista, era possuidor de uma média escravaria (VICENZI, 2015).

Legatários com famílias consanguíneas ou de parentesco refletem as vivências na escravaria na fazenda São João e, no pós-abolição, compartilham experiências sociais no território da Invernada dos Negros, constituindo-se em famílias negras extensas. De acordo com Claudia Molet (2018, p. 31):

A memória coletiva dos quilombolas traz inúmeros laços de reciprocidade que são fundados, principalmente, pelo reconhecimento de pertença a um mesmo grupo étnico, pelas redes de sociabilidade e pelas alianças matrimoniais que fortalecem as ligações étnico-culturais; além disso, a fundação destes quilombos aponta para laços de parentesco das primeiras famílias negras.

As famílias negras que permanecem na Invernada dos Negros, pois a acessaram legalmente (herança), constituíram e mantiveram relações de parentesco, de práticas culturais, de sociabilidades e de uso da terra. Nessa comunidade, o cultivo da terra e a criação de animais ensejava a dinâmica cotidiana de sobrevivência, e desenvolveu-se ali o campesinato negro. Nos aportamos em Rodrigo Weimer (2016) ao pesquisar a comunidade de Morro Alto, no litoral norte do Rio Grande do Sul, que evidencia a presença do campesinato negro.

Toma-se aqui, portanto, a existência de um campesinato brasileiro e, dentre esse, de um segmento negro com experiências e trajetórias históricas próprias. O econômico fazia desses negros, camponeses; o cultural e etnicorracial fazia desses camponeses, negros. (WEIMER, 2016, p. 22). 
No entanto, a certeza de que a terra e os alimentos ali produzidos, assim como os ensinamentos transmitidos pela oralidade dos mais velhos aos jovens, seria passada às próximas gerações não tardou em ser questionada e usurpada. Famílias de camponeses negros, em sua maioria analfabetos das letras e leis da República, começam a sentir as garras da "civilidade" do homem branco, que desejava medir, fracionar, "legalizar" e desapossar os herdeiros da propriedade herdada em testamento.

\section{Retalhamento do território}

Definido o território, entendido como um local de vivências que produz múltiplas experiências, da Invernada dos Negros com a posse dos legatários e seu estabelecimento, as terras ao seu entorno, o restante da então fazenda São João, foi gradativamente sendo retalhada e comercializada, significando a chegada de novos sujeitos naquela região. Embora partilhado, o imóvel continuou a ser ocupado de modo indiviso até que em 1909³, Domingos Bottini, um dos condôminos, entrou com uma Ação de Divisão de terras a fim de que se definissem os quinhões de cada um (LEITE et al., 2006). Essa ação resultou na primeira perda territorial dos legatários, e que descrevemos de forma sintetizada a seguir, para que o leitor possa melhor acompanhar posteriormente a análise da Ação de Divisão de 1928 a 1942 (TAFFAREL, 2019).

Sem condições econômicas para pagar as custas do processo da Ação de Divisão (1909), parte do território dos negros, conhecida como Invernadinha, foi leiloada e arrematada pelo próprio Bottini. Essa penhora, devemos registrar, ocorreu após decisão em primeira instância e enquanto acontecia a contestação de outros proprietários e do legatário Joaquim de Souza e Oliveira em instâncias superiores. Em uma delas, inclusive, o acórdão sobre a sentença determina as custas pelo apelado, no caso, Domingos Bottini. No entanto, apesar dessa determinação, essa parte territorial nunca mais foi retomada pelos negros (LEITE et al., 2006).

Cabe destacar ainda, que o processo ocorreu com diversas irregularidades, que são apontados posteriormente, como Domingos Bottini legislando em causa própria; não foi feita a primeira citação por meio de edital; Joaquim de Souza e Oliveira (um dos legatários) não recebeu notificação; não foi fixado o edital no foro da comarca, o que era obrigatório; irregularidades na medição; falta de compromisso de um dos arbitradores; e a penhora desde logo sobre as terras legadas em usufruto.

O juiz Antonio Gonçalves de Meira, na primeira instância, afirma na sentença que os legatários requereram que, "para garantia de pagamento da sua quota parte de custas e despesas da divisão, [...] fosse separado desde logo uma gleba de terras para sobre ela recair a execução, visto não disporem outros meios para pagarem tais custas e despesas" ${ }^{4}$ (TAFFAREL, 2019). Fica o questionamento acerca do (des)conhecimento dos legatários sobre a forma de pagamento e a conduta ética de quem redigiu o que foi subscrito pelo juiz, visto que os mesmos, em sua maioria, não tiveram acesso à escola formal, sendo analfabetos conforme consta nos documentos anexados ao longo do processo de Divisão da terra.

Nesse processo, há a presença do advogado Henrique Rupp Junior, a favor de Bottini, em 6 de junho de 1911. O advogado apareceu novamente na história da comunidade em 1928 quando o mesmo assinou a petição para a Ação de Divisão de terras da Invernada dos Negros, e passou a representar os legatários em outros processos judiciais referentes à terra a partir dessa data. A hipótese é, portanto, que foi neste momento/ ano que ele ficou sabendo da existência da comunidade e do legado da mesma, o que gerou seu interesse (TAFFAREL, 2019).

Ainda sobre o processo de Divisão, iniciado em 1909, destacamos que após saber que a divisão foi anulada, em novembro de 1913, Domingos Bottini foi até a Invernada dos Negros, na casa de Domingos Fernandes da Silva (viúvo da legatária Margarida), onde foi realizada uma escritura de ratificação de divisão e adjudicação de terras ${ }^{5}$ entre ele e os legatários e seus descendentes (vários são citados no texto). $\mathrm{O}$ documento dizia que os presentes se achavam satisfeitos com a divisão das terras, e ratificavam a divisão homologada pela sentença de $1^{a}$ Instância, e que não se sentiam de modo algum lesados ou prejudicados. Também relata que os legatários de Matheus José de Souza e Oliveira reconheciam como legalmente feita em favor de Bottini a adjudicação judicial da gleba de terras para pagamento da cota de custas e despesas judiciais e que esta se situava no Faxinal. Ou seja, mesmo sabendo da anulação da Ação de Divisão das terras da fazenda São João pelas diversas irregularidades citadas pelo Superior Tribunal de Justiça, Bottini foi até a residência de um dos legatários na Invernada dos Negros, para que os mesmos e seus descendentes assinassem o documento em que 
afirmavam estar satisfeitos com a divisão e ratificando a posse da Invernadinha do Faxinal ao mesmo como pagamento das custas, que foram $9.114 .100 \mathrm{~m}^{2}$ (TAFFAREL, 2019).

Como já destacado, a maioria dos moradores da Invernada dos Negros era analfabeta no momento da produção desse documento, vivendo em estado de vulnerabilidade social, sem acesso aos direitos básicos e à cidadania. Além disso, esse documento relata a presença de filhos menores, sendo muitos ainda crianças. É nesse contexto que Domingos Bottini redige uma carta com construções argumentativas para assegurar a posse, o domínio da área de terra, e sem ninguém para explicar aos negros/as que a sentença final era a derrota deles na ação. Os negros/as herdeiros/as dos legatários, afirmam ainda hoje, que confiaram nos homens letrados por muito tempo, mas que os mesmos somente se aproveitaram deles (TAFFAREL, 2019).

O que levou Bottini a legislar em causa própria? Certamente ele estava investido da superioridade de homem branco, da tão divulgada política do branqueamento e dos privilégios que a mesma garantia a homens que não tivessem sua história ligada ao cativeiro, quer próxima ou distante. E aqui reside ainda, a legislação. A abolição e a instituição da República não garantiram que os libertos usufruíssem da cidadania atribuída aos homens brancos, pois a lacuna entre 1888 e 1916 (BRASIL, [1919]), quando o código civil ficou pronto, possibilitou a homens como Domingos Bottini a exclusividade da condição de cidadão. Segundo Mattos, "uma vez abolida a escravidão, a codificação civil tardiamente realizada se fez a partir de um silêncio, ainda assim racializante, sobre o passado escravista". (MATTOS apud GRINBERG, 2002, p. 15). Nesta Ação de Divisão é recorrente a expressão ex-escravos, explicitando e reproduzindo o jogo de poder entre brancos e negros subalternos.

Em 1928, outra Ação de Divisão de terras resultou no retalhamento e perda de uma grande parcela do território da comunidade Invernada dos Negros, sendo que 50\% ficaram ao advogado em troca dos seus honorários. Após essa divisão, com território reduzido, famílias maiores e sem acesso a políticas públicas, muitos herdeiros acabaram buscando uma vida melhor fora da comunidade. Outros, para fugir da fome e do descaso, acabaram sendo expropriados, vendendo suas propriedades por menos do que elas valiam (LEITE, 2006).

Analisando o processo, iniciado em 1928 e finalizado em 1942, podemos destacar alguns documentos pertencentes ao processo e considerações. Um desses documentos, é a procuração ${ }^{6}$ em que os descendentes dos legatários nomeavam e constituíam o advogado Henrique Rupp Junior e o comerciante Paulo Blasi como seus procuradores a fim de promover a demarcação e divisão do imóvel. Outro, é o contrato de honorários datado de 15 de fevereiro de 1928 e foi redigido na casa do senhor José Maria Pereira, na Invernada dos Negros, indicando que havia intenções já planejadas pelo advogado (TAFFAREL, 2019).

O documento/contrato estabelece que eles promoveriam a demarcação e divisão do imóvel; que arcariam com todas as despesas com custas e impostos necessários para o andamento das causas, não sendo os legatários obrigados a quaisquer despesas, nem sequer teriam obrigação a qualquer indenização a qualquer tempo. No entanto, a cláusula terceira ${ }^{8}$ estabelece como indenização das custas e despesas, assim como para pagamento dos seus honorários, os contratantes deveriam escriturar a ele a metade das terras da Invernada dos Negros; e que essa escritura deveria ser assinada dentro de 30 dias depois de terminados os trabalhos de divisão do imóvel. Ainda, a outra metade seria dividida e partilhada em seis partes iguais entre os herdeiros ou sucessores dos primitivos escravos de Matheus José de Souza e Oliveira; que cada uma das seis famílias ficaria com o seu quinhão separado no lugar onde estivessem morando e ocupando com benfeitorias ou conforme melhor acomodação (TAFFAREL, 2019).

Os custos cobrados por Henrique Rupp Junior, o transformariam num senhor de terras (fazendeiro), e isto foi possível porque de acordo com o Código Civil de 1916 (BRASIL, [1919], não paginado):

Art. 624. O condômino é obrigado a concorrer, na proporção de sua parte, para as despesas de conservação ou divisão da coisa e suportar na mesma razão os ônus, a que estiver sujeita.

Parágrafo único. Se com isso não se conformar algum dos condôminos, será dividida a coisa, respondendo o quinhão de cada um pela sua parte nas despesas da divisão.

E ainda, garantia que mesmo se um dos herdeiros não cumprisse com o 'acordado' na procuração, os demais arcariam com o ônus: 
Art. 625. As dívidas contraídas por um dos condôminos em proveito da comunhão, e durante ela, obrigam o contratante; mas asseguram-lhe ação regressiva contra os demais.

Parágrafo único. Se algum deles não anuir, proceder-se-á conforme o parágrafo único do artigo anterior. (BRASIL, [1919], não paginado)

O advogado faz uso da prerrogativa que a legislação lhe garante para garantir seus benefícios. Ao longo da Ação e na sentença há descrição de que a intenção do testador (Matheus de Oliveira) foi louvável, pois os escravos eram 'conhecedores de pouca cultura e com deficiência de orientação', e o uso comum e perpétuo (sem comercializar ou hipotecar) garantiria a sobrevivência dos mesmos. No entanto, não estavam os legatários (condôminos) obrigados a conservar o condomínio: "é direito irrefragável do condomínio promover a divisão do imóvel comum"9 (BRASIL, [1919], não paginado). Pautado no artigo 1.666: "Quando a cláusula testamentária for suscetível de interpretações diferentes, prevalecerá a que melhor assegure a observância da vontade do testador" (Henrique Rupp Junior cria sua interpretação para que ocorra a divisão, visto que não contrariava os preceitos da lei (BRASIL, 1916, não paginado). Lei que os negros/as desconheciam para que pudessem refutar a interpretação do advogado.

A retórica do advogado, nos permite, pelo menos como hipótese, de que os sujeitos donos da terra da Invernada dos Negros, estavam em um nível inferior e, por si só, não eram cidadãos aptos a gerir sua herança. O que temos é a questão racial da Primeira República ${ }^{10}$ como eixo central para se entender as diferenças sociais e econômicas, as influências e os privilégios do advogado e dos condôminos.

Também, ressaltamos o depoimento do senhor Valeriano Ricardo da Silva, no qual ele afirma que nunca houve contestação quanto à propriedade da Invernada dos Negros, que sempre pertenceu aos legatários, e que sabia por que foi capataz da viúva de Matheus José de Souza e Oliveira, logo após o falecimento do mesmo. Esse depoimento nos traz alguns detalhes, como o fato do mesmo ter sido capataz da viúva Pureza Emília da Silva e ter sido ele a entregar as terras aos legatários. Era de conhecimento da comunidade local (Campos Novos), do testamento, da extensão de terras recebidas pelos legatários e a importância econômica da mesma, quer para criação de animais, para a agricultura ou para a extração de araucárias.

Em 1930, os agrimensores apresentaram o memorial descritivo ${ }^{11}$ onde observa-se que a Invernada dos Negros era atravessada por diversos arroios e riachos, sendo o maior, o lajeado da Corredeira. Naquele período, o território era composto por terras de cultura (cultivo de produtos) e de campos de criar sendo a maior parte de matas virgens. Existiam no terreno várias casas de moradia edificadas pelos proprietários, com benfeitorias. Ou seja, os negros estavam usufruindo do imóvel, fixaram residência no espaço construindo casas e utilizando a terra para subsistência e criação de animais. O memorial demonstra a existência do campesinato negro (TAFFAREL, 2019).

Ainda em 1930, Henrique Rupp Junior afirmou que em virtude do contrato firmado com os seus constituintes em 15 de fevereiro de 1928, requeria que, preliminarmente, o imóvel fosse dividido em duas partes iguais com campos e matos. Solicitou ainda que a dita metade dos herdeiros fosse subdividida em tantas partes iguais quantos eram os filhos dos ex-escravizados Manoel, Margarida e Damásia, sendo os falecidos representados por seus descendentes. O juiz Oscar Leitão determinou aos peritos que procedessem a divisão e que eles o consultassem sobre qualquer dificuldade encontrada. $\mathrm{O}$ documento não faz menção ao legatário Francisco e seus descendentes, que também constituíram família e habitavam na Invernada dos Negros.

A fim de executar esse contrato dos honorários ${ }^{12}$, Henrique Rupp Junior anexou o mesmo ao processo. A escritura pública teve como contratado Paulo Blasi e previu que ele poderia ceder o mesmo a outra pessoa, o que de fato ocorreu, já que ele passou a Henrique Rupp Junior.

Após o requerido pelo advogado, alguns condôminos entraram com pedidos ao juiz questionando o fato de que o mesmo resolveu que seria separado tal pagamento em uma só área de terras "e para isso escolheu a melhor parte do imóvel, dando-se ainda que desse modo virá compreender as moradas, cultivados e benfeitorias dos suplicantes, já no seu quinhão e já nos quinhões de outros condôminos"13 (ARQUIVO HISTÓRICO MUNICIPAL WALDEMAR RUPP apud TAFFAREL, 2019, p. 149). Os descendentes dos legatários solicitaram que o juiz determinasse que cada quinhão fosse formado com as terras contíguas as suas respectivas moradas, benfeitorias e cultivados. 
Os condôminos observam, portanto, que o advogado queria ficar com as melhores terras e acionam a justiça a fim de buscar seus direitos e permanecerem nas terras que tinham posse até então. Foram atendidos parcialmente, uma vez que seus lotes permaneceram onde havia suas moradias, mas em sua maioria sem acesso direto à estrada geral, isto é, isolados. Provavelmente as terras requeridas pelo advogado eram as de campo, já que os matos detinham a parte mais ondulada do território legado. Além disso, é importante destacar que Henrique Rupp Junior tinha a intenção de comercializar a terra recebida como honorários e custas, o que se concretizou posteriormente, pois o mesmo vendeu as terras para novos colonos e também para uma fábrica de papel e celulose. É a partir desse momento que a comunidade percebeu as maiores modificações no ambiente e na forma de vida (TAFFAREL, 2019).

Em 06 de abril de 1942, após quatorze anos da assinatura da procuração, o juiz Ricardo de Freitas descreveu na sentença: "E o contrato de honorários foi lavrado antes da vigência da lei que estabeleceu a porcentagem máxima de $20 \%$ para honorários de advogado" ${ }^{14}$. Fez-se a divisão, conforme apresentado no Quadro 1.

Na distribuição dos quinhões não foi nominado um dos filhos de Francisco dos Santos: o legatário João Francisco dos Santos ou seus descendentes. De acordo com Eliane Taffarel (2019, p. 126): "Francisco casou-se em 12 de outubro de 1878, com Maria Izabel do Espírito Santo, com quem teve três filhos: Maria Joana dos Santos; Manoel Francisco dos Santos e João Francisco dos Santos”. Já Francisco dos Santos casou-se com Firmina Padilha dos Santos e tiveram sete filhos: Generosa, Emídio, Francisco, Graciliano, Maria Antonia, Maria Francisca e Victor. A família do herdeiro Francisco dos Santos é ausente na distribuição dos quinhões concluída em 1942. Quiçá não se encontravam mais na comunidade da Invernada, e por isso tornaram-se inexistentes, ou invisibilizados foram excluídos aos olhos do representante legal (Henrique Rupp Junior).

A falta de informações detalhadas sobre os condôminos na distribuição dos quinhões demonstra lacunas/erros que geram problemas no processo de divisão, como a exclusão de herdeiro, mas ressaltamos que quando se refere aos benefícios do advogado Rupp Júnior, como a posse de 50\% do território, isso foi garantido (TAFFAREL, 2019).

A memória dos descendentes ${ }^{15}$ acerca dessa Ação de Divisão de terras, que resultou na perda e expropriação, é de que foram enganados por homens letrados ao afirmarem que a propriedade não poderia ficar da forma que estava, de forma usufrutuária, e isso confere com a descrição dos autos da Ação, em que a interpretação da lei (1916), desde que não lesasse por completo os herdeiros, a propriedade em comunhão/ condomínio poderia ser desfeita, e cada um receberia sua parte legalizada. Ouvindo a memória da comunidade e observando o contexto regional, Raquel Mombelli (2009) destaca que as frentes de colonização avançavam sobre os territórios e isso, somado a instalação de madeiras, deixava os moradores da Invernada em situação de fragilidade e de constante ameaça.

Efetivada a sentença em 1942, Henrique Rupp Junior inicia a comercialização da significativa área de terra que lhe pertencia. Contudo, não tardou para os legatários acionarem a justiça (comarca de Campos Novos). Eles solicitavam a revisão da aquisição de uma parte das terras pela empresa Ibicuí. Foi a Ação, na década de 1970, para que a empresa de celulose Ibicuí não se tornasse proprietária de uma das áreas do advogado. Infelizmente os legatários não saíram vitoriosos, e a partir daí a vida e a paisagem mudaram negativamente na Invernada dos Negros. Houve a introdução do pinus elliotti e do eucalipto para comercialização (TAFFAREL, 2019).

O documento (processo de Divisão) analisado revela como as terras inicialmente eram respeitadas como de posse dos descendentes dos legatários; como as mesmas geraram a cobiça dos colonizadores; e como isso acabou interferindo na persuasão para que os mesmos fizessem a divisão, com receio de que o testamento fosse anulado. Contudo, é preciso destacar que, por muitas vezes, fica a dúvida se a documentação foi produzida com o conhecimento e consentimento da comunidade negra, ou se o advogado fazia de acordo com o que lhe interessava. Fato é que em alguns momentos legatários sentiram-se lesados pelo advogado e reclamaram ao juiz que realizava a mediação, como na divisão em que as terras dos honorários não fossem contínuas. Certamente essa mediação garantiu os benefícios do advogado, pois mesmo não tendo seus quinhões contínuos, o mesmo permaneceu com a posse maior da área de campos.

Ainda, em meio às disputas pela terra cobiçada pelo avanço de fronteira agrícola, que implicou o recuo da fronteira do campesinato negro, intensificava-se a extração de madeira na região, especialmente de araucárias. Processos que causaram e causam dor, danos e inquietação à comunidade negra da Invernada dos Negros por mais de um século. Inquietação que os leva a reivindicar titulação e reparação. 
Quadro 1 - Auto de Divisão - 1942

\begin{tabular}{|c|c|c|c|}
\hline $\mathbf{N}^{\circ}$ Quinhão & Condôminos16 & Metragem - m2 & Valor - réis \\
\hline 01 & Maria Ribeiro*** & 1.248 .000 & $3.120 \$ 000$ \\
\hline 02 & Bernardino Caripuna $* * *$ & 1.248 .000 & $3.120 \$ 000$ \\
\hline 03 & Francisca Caripuna*** & 1.248 .000 & $3.120 \$ 000$ \\
\hline 04 & Sucessores de João Francisco*** & 1.248 .000 & $3.120 \$ 000$ \\
\hline 05 & Magdalena Caripuna*** & 1.248 .000 & $3.120 \$ 000$ \\
\hline 06 e 09 & Paulo Caripuna**** e Maria Joana**** & 1.248 .000 & $3.120 \$ 000$ \\
\hline 07 & Cypriano Caripuna*** & 1.248 .000 & $3.120 \$ 000$ \\
\hline 08 & Sebastião Fernandes** & 1.248 .000 & $3.120 \$ 000$ \\
\hline 10 & João Fernandes** & 1.248 .000 & $3.120 \$ 000$ \\
\hline 11 & Sucessores de Veneranda Caripuna*** & 1.248 .000 & $3.120 \$ 000$ \\
\hline 12 & Isidoro Caripuna*** & 1.248 .000 & $3.120 \$ 000$ \\
\hline 13 & Euphasio Caripuna*** & 1.248 .000 & $3.120 \$ 000$ \\
\hline 14 & José Caripuna*** & 1.248 .000 & $3.120 \$ 000$ \\
\hline 15 & Francisco Manoel de Souza* & 1.248 .000 & $3.120 \$ 000$ \\
\hline 16 & Candido Manoel de Souza* & 1.248 .000 & $3.120 \$ 000$ \\
\hline 17 & Leopoldina Fernandes** & 1.248 .000 & $3.120 \$ 000$ \\
\hline 18 & Manoel de Souza* & 1.248 .000 & $3.120 \$ 000$ \\
\hline 19 & Alexandrina Caripuna*** & 1.248 .000 & $3.120 \$ 000$ \\
\hline 20 & Sucessores Hercilia netos da legatária Damazia*** & 1.248 .000 & $3.120 \$ 000$ \\
\hline 21 & Herdeiros de Feliciana, netos do legatário Manoel* & 1.248 .000 & $3.120 \$ 000$ \\
\hline 22 & Manoel Francisco**** & 1.248 .000 & $3.120 \$ 000$ \\
\hline 23 & Sebastião Manoel de Souza* & 1.248 .000 & $3.120 \$ 000$ \\
\hline 24 & Braulina Fernandes $* *$ & 1.248 .000 & $3.120 \$ 000$ \\
\hline 25 & Margarida Maria de Souza* & 1.248 .000 & $3.120 \$ 000$ \\
\hline 26 & João Caripuna* & 1.248 .000 & $3.120 \$ 000$ \\
\hline 27 & Zacharias Fernandes $* *$ & 1.248 .000 & $3.120 \$ 000$ \\
\hline 28 & Balbina de Souza* & 1.248 .000 & $3.120 \$ 000$ \\
\hline 29 & Conceição Maria de Souza* & 1.248 .000 & $3.120 \$ 000$ \\
\hline 30 & Maria da Conceição Souza* & 1.248 .000 & $3.120 \$ 000$ \\
\hline 31 & João Manoel de Souza* & 1.248 .000 & $3.120 \$ 000$ \\
\hline 32 & Oliveira Caripuna*** & 1.248 .000 & $3.120 \$ 000$ \\
\hline 33 & $\begin{array}{l}\text { Dr. Henrique Rupp Junior - dividido nas glebas A, B, } \\
\text { C e D }\end{array}$ & 39.936 .000 & $\begin{array}{c}99.840 \$ 000 \text { (honorários, } \\
\text { despesas e custas do } \\
\text { processo) }\end{array}$ \\
\hline
\end{tabular}

Fonte: Ação de Divisão de Terras de 1928, folhas 114 - 136. Tombo no 1278. Arquivo Histórico Dr. Waldemar Rupp de Campos Novos/SC. (ARQUIVO HISTÓRICO MUNICIPAL WALDEMAR RUPP apud TAFFAREL, 2019)

Legenda:

* Descendentes de Manoel de Souza. ** Descendentes de Margarida Maria de Souza Fernandes. *** Descendentes de Damásia de Souza Caripuna. **** Descendentes de Francisco de Souza. 


\section{Considerações Finais}

"Foi então que uns brancos muito legais convidaram a gente pra uma festa deles, dizendo que era pra gente também". Esta é uma das frases da epígrafe transcrita pela intelectual negra Lélia Gonzalez (2020, p. 75). Ela nos diz muito sobre o lugar ocupado pelos brancos na pós-abolição, a construção sistêmica do racismo e seus discursos legitimadores.

Homens e mulheres cujas experiências foram negligenciadas e negadas: é isso que vemos ao longo do processo de Ação e Divisão das terras na Invernada dos Negros. Sem dúvida, as estratégias criadas pelos negros/ negras garantiram a manutenção de uma pequena porção de suas terras legadas. $\mathrm{O}$ trabalho do campesinato negro e as vivências os mantiveram ligados aos ancestrais.

Os detalhes que levaram os herdeiros a assinar a procuração em favor do advogado não estão descritos, mas revelam a disputa histórica da estrutura fundiária e os litígios de terras no Brasil.

A forma como transcorrem nos fazem questionar o que de fato era de conhecimento dos negros e como eles foram enganados pelos "homens da lei". Para além disso, os negros mantinham uma relação, inclusive de compadrio, com fazendeiros e comerciantes. Estes, como Bottini, no entanto, utilizam dessa relação e da confiança dos mesmos para usurpá-los.

E atualmente, embora a Constituição Federal, nossa Lei maior, determine a reparação das terras usurpadas na Invernada dos Negros e outras comunidades negras rurais, o que se vê é a morosidade dos processos e a continuidade da exclusão, do isolamento e do acesso à cidadania.

\section{Referências}

ARQUIVO HISTÓRICO MUNICIPAL WALDEMAR RUPP. Ação de Divisão de Terras de 1909. Tombo n 693. Campos Novos/SC. ARQUIVO HISTÓRICO MUNICIPAL WALDEMAR RUPP. Ação de Divisão de Terras de 1928. Tombo n 1278 . Campos Novos/SC. ARQUIVO HISTÓRICO MUNICIPAL WALDEMAR RUPP. Ação de Divisão Terras 1928-1942. Tombo nº 693. Campos Novos/SC. ARQUIVO HISTÓRICO MUNICIPAL WALDEMAR RUPP. Ação de Usucapião da Ascânio Bottini. Volume 1. Pasta: Ação Ordinária - 1953. Tombo: s/n. Campos Novos/SC.

ARQUIVO HISTÓRICO MUNICIPAL WALDEMAR RUPP. Testamento 1877. Tombo nº 693. Campos Novos/SC.

BRASIL. [Constituição (1988)]. Constituição da República Federativa do Brasil de 1988. Brasília, DF: Presidência da República, 1988. Disponível em: http://www.planalto.gov.br/ccivil_03/constituicao/constituicao.htm. Acesso em: 02 out. 2020.

BRASIL. Lei n ${ }^{\circ} 3.071$, de $1^{\circ}$ de janeiro de 1916. Código Civil dos Estados Unidos do Brasil. Brasília, DF: Presidência da República, 1916. Disponível em: http://www.planalto.gov.br/ccivil_03/leis/l3071.htm. Acesso em: 22 ago. 2020.

GONZALEZ, L. Por um feminismo afro-latino-americano: ensaios, intervenções e diálogos. Rio de Janeiro: Zahar, 2020.

GRINBERG, K. O fiador dos brasileiros: Cidadania, escravidão e direito civil no tempo de Antônio Rebouças. Rio de Janeiro: Civilização Brasileira, 2002.

GRINBERG, K. Código Civil e Cidadania. Rio de Janeiro, Jorge Zahar, 2001.

LEITE, I. B. et al. Quilombos no sul do Brasil: perícias antropológicas. Boletim Informativo do NUER, v. 3, n. 3, Florianópolis, 2006. MOLET, C. D. G. Parentescos, solidariedades e práticas culturais: estratégias de manutenção de um campesinato negro no litoral Negro do Rio Grande do Sul (do século XIX ao tempo presente). 2018. Tese (Doutorado em História) - Programa de Pós-Graduação em História. Universidade Federal do Rio Grande do Sul, Porto Alegre, 2018.

MOMBELLI, R. Relatório Antropológico: a Comunidade de Invernada dos Negros. Projeto quilombos no sul do Brasil: estudos antropológicos com vistas à implementação do Decreto 4.887. Florianópolis: NUER/UFSC, 2005.

MOTTA, Márcia. Brecha negra em livro branco: Artigo 68, remanescentes de quilombos e grilagens no Brasil. In: XII Encontro Regional de História - Usos do Passado- Anpuh - Rio de Janeiro, 2006.

MOURA, G. Quilombos contemporâneos no Brasil. In: CHAVES, R.; SECCO, C.; MACÊDO, T. (org.) Brasil África: como se o mar fosse mentira. São Paulo: Editora UNESP; Luanda, Angola: Chá de Caxinde, 2006. p. 327-362.

NOTA de esclarecimento da ocupação do território da Invernada dos Negros, em domínio da empresa Imaribo. Desacato, Florianópolis, 16 out. 2018. Disponível em: http://desacato.info/nota-de-esclarecimento-da-ocupacao-do-territorio-da-invernada-dos-negros-emdominio-da-empresa-imaribo/. Acesso em: 10 out. 2020.

RIOS, A. L.; MATTOS, H. Memórias do cativeiro: família, trabalho e cidadania no pós-abolição. Rio de Janeiro: Civilização Brasileira, 2005 . 
SCHWARCZ, L. M. O espetáculo das raças: cientistas, instituições e questão racial no Brasil, 1870- 1930. São Paulo: Companhia das Letras, 1993.

TAFFAREL, E. Da Fazenda São João à Comunidade Quilombola Invernada dos Negros: Terra, Trajetória e Permanência. 2019. Dissertação (Mestrado em História) - Programa de Pós-Graduação em História, Universidade Federal da Fronteira Sul, Chapecó, 2019.

TAFFAREL, L.; VICENZI, R. Quilombolas: História, Identidade e Direitos Pela Titulação de Seu Território, 2003 - Tempo Presente, Campos Novos/SC. In: Anais do XVI Encontro Estadual de História da ANPUH-SC: História e Movimentos Sociais. Chapecó, 2016. Disponível em: http://www.encontro2016.sc.anpuh.org/resources/anais/43/1464377691_ARQUIVO_artigoANPUHsemoresumo.pdf. Acesso em: 05 dez. 2019.

VICENZI, R. Nos campos de cima da serra: ser preto, pardo e branco na vila de Lages, 1776-1850. 2015. Tese (Doutorado em História) - Programa de Pós-Graduação em História, Universidade Vale do Rio dos Sinos, 2015.

WEIMER, R. de A. Os camponeses do Morro Alto: família e trabalho no litoral norte do Rio Grande do Sul no pós-Abolição (18901930). Porto Alegre: FEE, 2016. Disponível em: https://arquivofee.rs.gov.br/wp-content/uploads/2016/01/20160125e-book-final.pdf. Acesso em: 05 dez. 2019.

\section{Notas}

Testamento 1877. Tombo nº 693. Arquivo Histórico Dr. Waldemar Rupp. Campos Novos/SC.

Ação de Divisão Terras 1928. Tombo n 1278. Arquivo Histórico Dr. Waldemar Rupp. Campos Novos/SC.

Ação de Divisão de Terras - 1909. Tombo nº 693. Arquivo Histórico Dr. Waldemar Rupp. Campos Novos/SC.

4 Sentença - Folhas 70 a 73 da Ação de Usucapião da Ascânio Bottini. Volume 1. Pasta: Ação Ordinária - 1953. Tombo: s/n. Arquivo Histórico Dr. Waldemar Rupp. Campos Novos/SC.

5 Folhas 97 e 98 da Ação de Divisão de Terras - 1928. Tombo nº 1278. Arquivo Histórico Dr. Waldemar Rupp. Campos Novos/SC.

6 Ação de Divisão de Terras - 1928. Tombo 1278. Arquivo Histórico Dr. Waldemar Rupp. Campos Novos/SC.

7 Folhas 93 e 94 - Ação de Divisão de Terras -1928. Tombo n 1278. Arquivo Histórico Dr. Waldemar Rupp. Campos Novos/SC. Ação de Divisão de Terras -1928, folhas 93. Tombo n 1278. Arquivo Histórico Dr. Waldemar Rupp. Campos Novos/SC.

Ação de Divisão de Terras - 1928, olhas 165, 166. Tombo nº 1278. Arquivo Histórico Dr. Waldemar Rupp. Campos Novos/SC. Indicamos a leitura de Schwarcz, 1993.

Ação de Divisão de Terras - 1928, folha 66. Tombo nº 1278. Arquivo Histórico Dr. Waldemar Rupp. Campos Novos/SC.

Folhas 93 e 94 - Ação de Divisão de Terras -1928. Tombo n 1278. Arquivo Histórico Dr. Waldemar Rupp. Campos Novos/SC.

Folha 107 - Ação de Divisão de Terras - 1928. Tombo n 1278. Arquivo Histórico Dr. Waldemar Rupp. Campos Novos/SC.

4 Folha 167 - Ação de Divisão de Terras - 1928. Tombo nº 1278. Arquivo Histórico Dr. Waldemar Rupp. Campos Novos/SC.

15 Compreendemos a memória destes homens e mulheres a partir de: "As pessoas recordam individualmente, mas adquirem essas lembranças, mantêm-nas e recontam-nas socialmente - e é isso que as torna coletivas”. (RIOS; MATTOS, 2005, p. 9).

16 Optamos por manter a grafia dos nomes como consta no processo.

\section{Renilda Vicenzi}

reby.vicenzi@gmail.com

Doutorado em História - UNISINOS/RS

Professora do Curso de História e do PPGE. Universidade Federal da Fronteira Sul - Campus Chapecó

\section{Eliane Taffarel}

elianetaffarel@gmail.com

Mestre em História - UFFS/Campus Chapecó

Professora da rede pública Municipal de Chapecó/SC

\section{UFFS - Campus Chapecó}

Rodovia SC 484 - Km 02, Fronteira Sul

Chapecó - Santa Catarina - Brasil

CEP 89815-899 
Agradecimentos

Não se aplica.

Agência financiadora

Não se aplica.

Contribuições das autoras

$\mathrm{O}$ artigo foi elabora pelas autoras em todas as partes.
Aprovação por Comitê de Ética

Não se aplica.

Consentimento para publicação

Consentimento das autoras.

Conflito de interesses

Não há conflito de interesses. 